\title{
Um modelo para personalização de aprendizagem baseado em Gamificação e Learning Analytics
}

\author{
Aline de Campos \\ Programa de Pós-graduação em Informática na Educação \\ Universidade Federal do Rio Grande do Sul (UFRGS) - Porto Alegre - RS - Brasil \\ Orientador: Dr. Sílvio César Cazella Tempo de trabalho: Doutorado - 18 meses

\begin{abstract}
Resumo. Este artigo apresenta a proposta de construção de um modelo para personalização de aprendizagem com uso de processos de gamificação e apoiado por uma interface interativa de Learning Analytics capaz de prover dados diagnósticos e preditivos como forma de auxiliar o docente no acompanhamento do desempenho de alunos de Ensino Superior. Trata-se de uma pesquisa em andamento de natureza explicativa, em fase inicial de modelagem do método e construção dos recursos tecnológicos. Espera-se colaborar com o desenvolvimento de competências técnicas, humanas e gerenciais nos alunos e prover maior otimização de tempo e indicações assertivas aos docentes em processos de personalização de aprendizagem.
\end{abstract}

\section{Contextualização e motivação}

O âmbito educacional há muito tempo vem sendo impactado com a introdução de tecnologias de informação e comunicação nos seus diversos processos. Ao encontro disso, o perfil dos estudantes está mudando e exigindo métodos de aprendizagem mais dinâmicos. Mais do que nunca é importante conhecer o perfil do aluno e conseguir demonstrar a real importância das competências propostas para seu desenvolvimento, bem como de que forma serão aplicadas na vida pessoal e profissional. Sendo assim, a inovação na educação pode ser a diferença no desempenho de alunos durante sua formação acadêmica e no desenvolvimento de indivíduos mais autônomos e preparados para as dinâmicas atuais.

Nesse sentido, segundo King et al. (2016), caminham-se para cenários de mudanças graduais que movem a educação da tradicional experiência homogênea que prevê a adoção de uma lógica de um para muitos, para vivências centradas na aprendizagem, muito mais imersivas e focadas na personalização.

Isso faz com que os papéis de estudante e educador sejam fortemente implicados por esse contexto. Os alunos podem ter acesso a abordagens customizadas para o desenvolvimento de sua aprendizagem partir de estruturas que se encaixem às suas necessidades e não apenas ao tradicional e determinado de maneira genérica para toda uma turma. Já os docentes podem assumir uma postura de orientador, ampliando sua relevância na curadoria de experiências de aprendizagem.

Mesmo diante desse cenário profícuo, encontram-se dois grandes desafios: a necessidade de práticas mais ativas, atrativas e engajadoras aos alunos, no sentido de estimular seu envolvido no desenvolvimento de conhecimentos e de competências; e a otimização da carga de trabalho do docente diante da demanda pela concepção e acompanhamento de processos centrados na personalização de aprendizagem. 
Uma estratégia que vem sendo adotada há muitos anos em diversas áreas e que tem sido inserida na área educacional é a gamificação, também conhecida como ludificação. Para Domínguez et al. (2013) trata-se da utilização de dinâmicas, mecânicas, estéticas e narrativas de jogos, em contextos que não sejam especificamente de jogos. Alguns estudos já apontam para o potencial dessa prática enquanto processo de estímulo ao engajamento e produção por parte dos alunos e esta parece ser uma abordagem interessante em busca de soluções para o primeiro desafio indicado.

No que diz respeito ao segundo desafio apresentado, percebe-se que a concepção de experiências de aprendizagem centradas no estudante demandam um forte papel de orientador por parte do docente, acarretando a necessidade de coletas de dados, registros e análise constante. Desde o planejamento da aplicação, passando pela construção de atividades que levem em consideração os perfis dos alunos, até o processo de gestão do progresso, avaliação dos resultados e das competências desenvolvidas, torna-se desgastante ao docente a carga de trabalho gerada dentro de um processo tomado muitas vezes por incertezas.

Sabe-se da grande produção de dados no âmbito educacional, o que muitas vezes pode resultar em subutilização. Segundo Costa et. al (2013) boa parte desses dados não tem sido analisado, considerando que informações ricas podem ser extraídas. Em busca de reverter esse quadro, a área de Learning Analytics (LA) tem despontado na abertura de maior entendimento dos processos educacionais e do perfil dos alunos através de dados.

Segundo Moissa et al. (2015) esta área trata da realização de coleta, medição, análise e sistematização dos dados educacionais e seus contextos. $\mathrm{O}$ principal aspecto reside no processo realizado em ciclos que consideram a intervenção humana. Procura-se entender o contexto em uma abordagem holística onde dados em larga escala proporcionam possibilidades de avaliação, compreensão de problemas e planejamento de intervenções [Siemens e Baker, 2012].

Entretanto ainda encontram-se poucos recursos direcionados a apoiar os docentes e implicar positivamente em sua prática diária. Assim, existe um campo de estudos a serem explorados no sentido de integrar práticas de gamificação e interfaces de análise de dados para tomada de decisão ampliando as possibilidades de processos de personalização de aprendizagem.

Assim, esta proposta centra-se na seguinte questão de pesquisa: Como um modelo de personalização de aprendizagem suportado por gamificação e Learning Analytics pode influenciar o desempenho de alunos do Ensino Superior?

\section{Solução proposta}

Propõe-se, portanto, um modelo de personalização de aprendizagem com uso de estratégias de gamificação e análise de dados através de uma interface de Learning Analytics no sentido de dar suporte aos docentes e influenciar no desempenho dos estudantes numa perspectiva que contemple o novo perfil de alunos do chegam ao Ensino Superior. Neste estudo assume-se desempenho como sendo o conjunto de competências técnicas, humanas e gerenciais desenvolvidas pelo aluno durante uma unidade curricular, levando-se em conta o seu engajamento nas experiências de aprendizagem. 
VIII Congresso Brasileiro de Informática na Educação (CBIE 2019)

Anais dos Workshops do VIII Congresso Brasileiro de Informática na Educação (WCBIE 2019)

Do ponto de vista de implementação de práticas de gamificação e coleta de dados dos estudantes, este projeto fará uso de um aplicativo já existente, denominado Kolligo ${ }^{1}$. Conforme demonstra a Figura 1, trata-se de um aplicativo para dispositivos com o qual educadores podem construir práticas didáticas usando os recursos que considerarem mais adequados ao contexto. A versão atual desenvolvida para plataforma Android e iOS, conta com as seguintes principais recursos: questionários com possibilidade de acompanhamento das respostas em tempo real por parte dos docentes; pontuação e ranking configuráveis; emblemas de reconhecimento e feedback; cartas de recompensas para estimular a autonomia e tomada de decisão do estudante ${ }^{2}$.

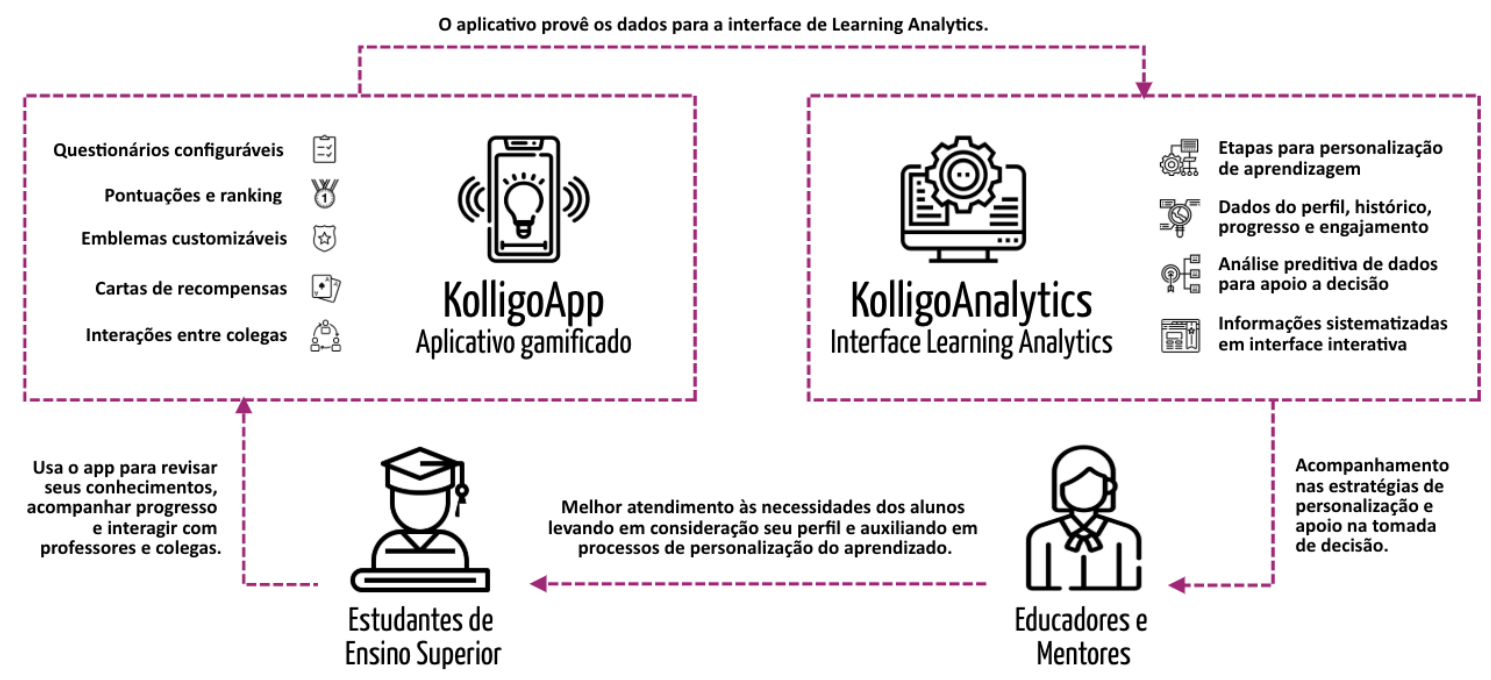

Figura 1. Sistematização da proposta de pesquisa.

Pretende-se a partir dos dados coletados por este aplicativo desenvolver uma plataforma de Learning Analytics voltada aos educadores. A partir de um modelo de personalização de aprendizagem que leve em conta o uso de práticas gamificadas, $\mathrm{o}$ docente poderá conhecer o perfil dos alunos, conhecer seu histórico e acompanhar o desempenho, bem como ter indicações via análise diagnóstica e análise preditiva de dados que podem auxiliar na tomada de decisão. Por sua vez, estas análises podem influenciar nas escolhas do docente quanto às práticas de gamificação adotadas para cada aluno ou turma, num processo de retroalimentação.

Serão aplicados processos de mineração com apoio de técnicas de machine learning, A partir disso, pretende-se oferecer um ambiente com a sistematização de informações relevantes para tomada de decisão do docente num processo que amplie as possibilidades de desenvolvimento de experiências de aprendizagem personalizada.

\footnotetext{
${ }^{1}$ Anteriormente o aplicativo chamava-se Colligo, adotando-se a partir de Fevereiro de 2019 o nome Kolligo por uma estratégia de divulgação e expansão.

${ }^{2}$ Mais informações em Wiener, Alice M.; Campos, Aline de. Colligo App: gamificação em sala de aula. VII Congresso Brasileiro de Informática na Educação (CBIE 2018). Anais dos Workshops do VII Congresso Brasileiro de Informática na Educação, 2018. Disponível em: https:/www.br-ie.org/pub/index.php/wcbie/article/view/8241/5920.
} 
VIII Congresso Brasileiro de Informática na Educação (CBIE 2019)

Anais dos Workshops do VIII Congresso Brasileiro de Informática na Educação (WCBIE 2019)

\section{Aspectos metodológicos}

Esta pesquisa apresenta-se como de natureza aplicada e pode ser classificada quanto ao seus objetivos como explicativa. Segue uma abordagem mista, que envolve tanto enfoque quantitativo, quanto qualitativo de maneira complementar. Quanto aos procedimentos, trata-se de uma pesquisa de modalidade quase-experimento com uso de métodos de fichamentos, observações e entrevistas. Serão realizados processos de prototipação para validação dos recursos tecnológicos desenvolvidos e atividades em campo, uma vez que pretende-se aplicar em cenários de Ensino Superior. Trata-se de um projeto em andamento e a Figura 2 demonstra o delineamento preliminar das etapas.

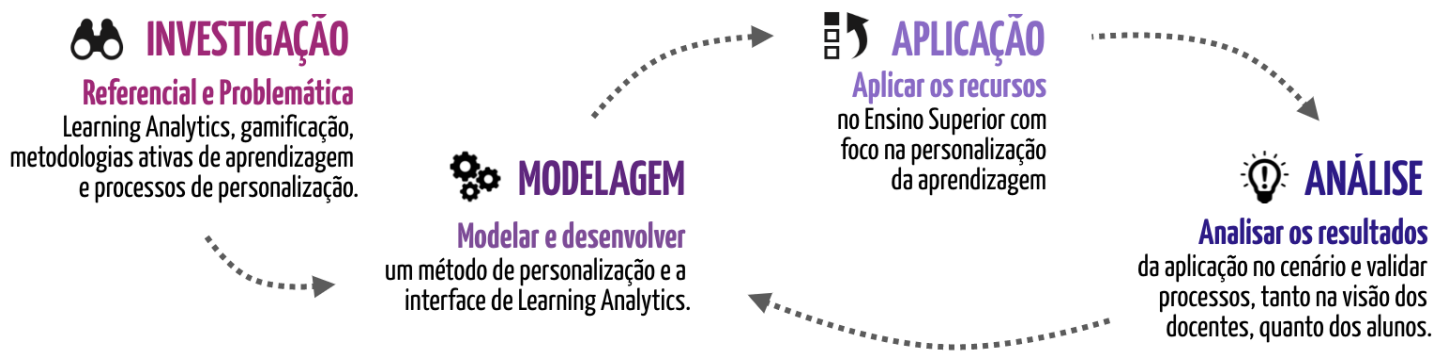

Figura 2. Delineamento preliminar de etapas da pesquisa.

Inicialmente busca-se verificar as potencialidades da integração de Learning Analytics em processos de personalização de aprendizagem, as possíveis correlações com o uso de gamificação e implicações com questões de desempenho e engajamento. Essa etapa está sendo desenvolvida através de construção de referencial teórico, análise de trabalhos correlatos com revisão sistemática de literatura ${ }^{3}$, bem como análise de recursos técnicos já disponíveis e sua utilização em contextos de Ensino Superior.

Ao encontro disso, pretende-se modelar e desenvolver um método de personalização de aprendizagem fazendo uso de gamificação e Learning Analytics, bem como construir a interface que de forma interativa possa apoiar o processo e tomada de decisão por parte dos docentes. Espera-se aplicar os recursos desenvolvidos em cenários de educação no Ensino Superior para validação do modelo e dos recursos técnicos.

Ao analisar os resultados da aplicação nesses cenários pretende-se verificar suas implicações, tanto na visão dos docentes, quanto dos alunos. Acredita-se que esses resultados serão capazes de retroalimentar a modelagem no sentido de aplicar melhorias num processo iterativo e incremental a fim de obter resultados mais assertivos acerca da implicação no desempenho dos alunos.

\section{Resultados esperados}

Pretende-se que este estudo possa contribuir com a área de Informática na Educação no sentido de explorar e validar as potencialidades da gamificação em união aos recursos de

\footnotetext{
3 Revisão sistemática de literatura publicada em: Campos, Aline de; Cazella, Sílvio C. Learning Analytics em processos de personalização de aprendizagem: uma revisão sistemática de literatura. RENOTE - Revista Novas Tecnologias na Educação, v. 16, n. 1, 2018. Disponível em: https://seer.ufrgs.br/renote/article/view/86028.
} 
VIII Congresso Brasileiro de Informática na Educação (CBIE 2019)

Anais dos Workshops do VIII Congresso Brasileiro de Informática na Educação (WCBIE 2019)

Learning Analytics no apoio aos docentes e no desempenho de alunos a partir de processos de personalização no Ensino Superior.

Espera-se a partir do desenvolvimento dessas interfaces, ampliar as capacidades dos docentes na construção de sua prática no sentido de fornecer informações sistematizadas capazes de gerar indicações sobre seus alunos dentro do domínio das competências relacionadas a sua disciplina. Ou seja, capaz de prover assistência ao docente e não a tentativa de substituição de seu papel fundamental no processo de ensino e aprendizagem. Com esses recursos espera-se que a sobrecarga docente possa ser minimizada, tornando-se aliado no processo de tomada de decisão, liberando os professores para seu verdadeiro papel intelectual de condutor das experiências de aprendizagem no sentido de planejar e orientar os processos para cada estudante [Horn e Staker, 2015].

Em cenários de Ensino Superior, acredita-se que o modelo pode auxiliar num melhor atendimento do desenvolvimento de competências dos alunos. A medida em que avança em sua formação, mais dados são coletados e melhor torna-se sua experiência e a dos docentes que podem se sentir mais preparados e embasados por dados na tomada de decisão. A função do professor passa ao plano de maior importância na condução das experiências de aprendizagem levando em conta seus conhecimentos e vivências e menos em processos manuais e burocráticos, incentivando o desenvolvimento de competências humanas, técnicas e gerenciais nos estudantes e a formação de cidadãos mais conscientes do seu potencial e suas singularidades.

\section{Referências}

Costa, E., Aguiar, J., Magalhães, J. (2013). "Sistemas de Recomendação de Recursos Educacionais: conceitos, técnicas e aplicações”. In: Anais da II Jornada de Atualização em Informática na Educação do II Congresso Brasileiro de Informática na Educação.

Domínguez, A.; Navarrete, J. S.; Marcos, L.; Sanz, L. F.; Pagés, C.; Herráiz, J. J. M. (2013). "Gamifying learning experiences: Practical implications and outcomes". In: Journal Computers \& Education, p. 380-392

Horn, M. B.; Staker, H. (2015). Blended: usando a inovação disruptiva para aprimorar a educação. Tradução: Maria Cristina Gularte Monteiro. Porto Alegre: Penso.

King, M.; Cave, R.; Foden, M.; Stent, M. (2016). Personalised Education - From curriculum to career with cognitive systems. IBM Education. IBM Corporation, UK.

Moissa, B.; Gasparini, I.; Kemczinski, A. (2015) "Educational Data Mining versus Learning Analytics: estamos reinventando a roda? Um mapeamento sistemático". In: Anais do XXVI Simpósio Brasileiro de Informática na Educação no Congresso Brasileiro de Informática na Educação.

Siemens, G.; Baker, R. S. (2012). "Learning Analytics and Educational Data Mining: Towards Communication and Collaboration". In: Proceedings of the 2nd international conference on learning analytics and knowledge. ACM. 252-254. 